\title{
Arterial stiffness estimation in healthy subjects: a validation of oscillometric (Arteriograph) and tonometric (SphygmoCor) techniques
}

\author{
Margareta Ring ${ }^{1,2}$, Maria Jolanta Eriksson ${ }^{1,2}$, Juleen Rae Zierath ${ }^{3}$ and Kenneth Caidahl ${ }^{1,2}$
}

Arterial stiffness is an important cardiovascular risk marker, which can be measured noninvasively with different techniques. To validate such techniques in healthy subjects, we compared the recently introduced oscillometric Arteriograph (AG) technique with the tonometric SphygmoCor (SC) method and their associations with carotid ultrasound measures and traditional risk indicators. Sixty-three healthy subjects aged 20-69 (mean 48 \pm 15 ) years were included. We measured aortic pulse wave velocity $\left(P W V_{a 0}\right.$ ) and augmentation index (Alx) by $A G$ and $S C$, and with $S C$ also the $\mathrm{PWV}_{\mathrm{ao}}$ standardized to $80 \%$ of the direct distance between carotid and femoral sites (St-PWV $\left.{ }_{a 0} \mathrm{SC}\right)$. The carotid strain, stiffness index and intima-media thickness (cIMT mean $)$ were evaluated by ultrasound. PWV ${ }_{a 0} A G\left(8.00 \pm 2.16 \mathrm{~m} \mathrm{~s}^{-1}\right)$ was higher $(P<0.001)$ than $\mathrm{PWV}_{\mathrm{ao}} \mathrm{SC}$ $\left(6.87 \pm 1.47 \mathrm{~m} \mathrm{~s}^{-1}\right)$, but did not differ from St-PWV ${ }_{\mathrm{ao}} \mathrm{SC}\left(7.68 \pm 1.58 \mathrm{~m} \mathrm{~s}^{-1}\right)$, and correlated $(P<0.001)$ with both $(r=0.54$ and 0.59). St-PWV $\mathrm{ao}_{\mathrm{S}} \mathrm{SC}$ was significantly $(P<0.01)$ higher than $\mathrm{PWV}_{\mathrm{ao}} \mathrm{AG}$ for values below median $\left(7.4 \mathrm{~m} \mathrm{~s}^{-1}\right)$. $\mathrm{PWV}$ ao by SC and AG differed significantly in females $(P<0.001)$, but not in males $(P=0.40)$. Alx $x_{a 0} A G(27.5 \pm 14.5 \%)$ was higher $(P<0.001)$ than Alx $\mathrm{x}_{\mathrm{ao}} \mathrm{SC}(20.5 \pm 17.4 \%)$, but related closely $(r=0.97, P<0.001)$. St-PWV $\mathrm{ao}_{0} \mathrm{SC}, \mathrm{PWV}_{\mathrm{ao}}$ and Alx $\mathrm{a}_{\mathrm{ao}}$ by SC, and $\mathrm{PWV}_{\mathrm{ao}}$ and $A \mathrm{x}_{\mathrm{ao}}$ by $\mathrm{AG}$ were all related to serum cholesterol and to $\mathrm{cIMT}_{\text {mean }}(\boldsymbol{P}<0.001)$. Arterial stiffness indices by $A G$ and SC correlate with vascular risk markers in healthy subjects. Alx $\mathrm{a}_{\mathrm{ao}}$ results by $\mathrm{AG}$ and $\mathrm{SC}$ are closely interrelated, but higher values are obtained by AG. In the lower range, $P W V_{a o}$ values by AG and SC are similar, but differ for higher values. Our results imply the necessity to apply one and the same technique for repeated studies.

Hypertension Research (2014) 37, 999-1007; doi:10.1038/hr.2014.115; published online 24 July 2014

Keywords: augmentation index; cardiovascular; healthy subjects; intima-media thickness; pulse wave velocity

\section{INTRODUCTION}

Cardiovascular $(\mathrm{CV})$ risk stratification and detection of early vascular aging are becoming more important in everyday clinical practice, and noninvasive techniques to measure arterial stiffness are warranted. Arterial stiffness, an important marker of CV risk, is an independent predictor of all-cause CV morbidity and mortality. ${ }^{1}$ Arterial stiffness, measured as aortic pulse wave velocity $\left(\mathrm{PWV}_{\mathrm{ao}}\right)$ and augmentation index (AIx), is an independent risk predictor in coronary artery disease $^{2,3}$ and hypertension, ${ }^{4}$ and it is present in the general population., $\mathrm{PWV}_{\mathrm{ao}}$ is also associated with all-cause and $\mathrm{CV}$ mortality in hypertensive patients, ${ }^{1}$ as well as CV mortality in the general population. ${ }^{5}$

The pulse augmentation is explained as the pressure differences between the forward traveling pulse wave, which is generated by the left ventricular systolic ejection and the returning pulse wave reflected from peripheral arteries. Increased arterial stiffness causes an earlier reflected pulse wave in the central aorta. ${ }^{7}$ Changes in the wave reflection properties are associated with aging, vascular disease and an increase in left ventricular afterload. ${ }^{7} \mathrm{PWV}_{\mathrm{ao}}$, measured between the carotid and the femoral artery, is considered as the 'gold-standard' noninvasive measurement of arterial stiffness, according to current expert consensus. ${ }^{8}$ Two techniques suitable for clinical practice are available for measuring $\mathrm{PWV}_{\mathrm{ao}}$. First, a tonometric technique used by SphygmoCor (SC) (AtCor Medical, Sydney, NSW, Australia) determines AIx from the pulse wave of the radial artery and $\mathrm{PWV}_{\mathrm{ao}}$ from pulse wave recordings from two sites, namely carotid and femoral artery. Second, the oscillometric method used by the Arteriograph (AG) (TensioMed, Budapest, Hungary) allows simultaneous recordings of $\mathrm{AIx}$ and $\mathrm{PWV}_{\mathrm{ao}}$ during cuff occlusion of the brachial artery.

Increased intima-media thickness in the carotid artery (cIMT) is associated with an increased risk of myocardial infarction and stroke in older adults, ${ }^{9}$ and is related to aortic stiffness in subjects with and without type 2 diabetes. ${ }^{10-12}$

${ }^{1}$ Section of Clinical Physiology, Department of Molecular Medicine and Surgery, Karolinska Institutet, Stockholm, Sweden; ${ }^{2}$ Department of Clinical Physiology, Karolinska University Hospital, Karolinska University Hospital, Stockholm, Sweden and ${ }^{3}$ Section of Integrative Physiology, Department of Molecular Medicine and Surgery, Karolinska Institutet, Stockholm, Sweden

Correspondence: M Ring, Department of Clinical Physiology, Karolinska Institutet, Karolinska University Hospital N2:01, Solna, 17176 Stockholm, Sweden. E-mail: margareta.ring@ki.se

Received 27 December 2013; revised 29 May 2014; accepted 6 June 2014; published online 24 July 2014 
SC and AG techniques have been compared, mostly for single variables, in patients with $\mathrm{CV}$ diseases, ${ }^{13-16}$ but not in healthy individuals. Thus, we determined the associations between these measures by both techniques and cIMT and carotid wall elasticity by ultrasound in healthy subjects.

\section{METHODS}

\section{Subjects}

Sixty-three healthy non-smoking subjects ( 21 men and 42 women) between 20 and 69 years of age, without known hypertension, diabetes mellitus or renal disease, and no medication affecting the CV system, were included. The subjects were selected from the population registry of the city of Stockholm and from advertising. All subjects were studied after at least $4 \mathrm{~h}$ of fasting and with no caffeine intake from midnight the night before examination.

The common carotid artery (CCA) was examined after a 30-min period of rest in supine position in a quiet room. Thereafter, pulse wave recordings were acquired by SC followed by AG investigation. The same sequence of investigations was kept for all study subjects, as the SC investigation involves minimal influence on the arm arteries, whereas the AG investigation involves periods of suprasystolic pressure.

All measurements were performed by the same investigator. Each participant provided written consent to participate in the study, which was approved by the Regional Ethics Review Board of Stockholm, Sweden.

\section{Arteriograph}

The AG is based on an oscillometric method using the occlusion technique. Patient data and the measured distance between the jugulum and the symphysis were registered in the AG programmed computer (TensioMed Software v.1.9.9.2; TensioMed, Budapest, Hungary). A tape measure was used for measuring the jugulum and the symphysis distance, namely the aortic distance. The cuff was placed on the patient's upper arm and connected to the device. Pressure variations in the cuff influenced a pressure receptor and the signal was transferred via an infrared port to the computer. The blood pressure (BP) in the upper arm was measured at an initial cuff inflation, and at a second inflation at $35 \mathrm{~mm} \mathrm{Hg}$ above the systolic BP: the pressure pulse configuration was recorded. The algorithm measuring BP in the AG device has been validated. ${ }^{17}$ The basis of the technique is the generation of two systolic peaks. First, there is an early systolic pressure peak (P1) created by the ejection of the blood volume from the left ventricle into the aorta. The pressure wave is transmitted to the lower part of the body and the reflected wave from the periphery (average assumed around the aortic bifurcation) generates the late systolic peak (P2). Pulse pressure (PP) is the difference in systolic and diastolic $\mathrm{BP}$ (in $\mathrm{mm} \mathrm{Hg})$. Both aortic $\mathrm{AIx}\left(\mathrm{AIx}_{\mathrm{ao}}\right)$ and brachial $\mathrm{AIx}\left(\mathrm{AIx}_{\mathrm{br}}\right)$ is calculated as $100 \times(\mathrm{P} 2-\mathrm{P} 1) / \mathrm{PP}$. The return time (RT) is the difference (in ms) between the first (P1) and reflected systolic wave (P2) and is related to the stiffness of the aorta. $\mathrm{PWV}_{\mathrm{ao}}$ was calculated as the jugulum and the symphysis distance (m) divided by return time (RT/2) (s). The $\mathrm{PWV}_{\mathrm{ao}}$ and $\mathrm{AIx}_{\mathrm{ao}}$ are presented as mean values from two recordings. For $\mathrm{PWV}_{\mathrm{ao}}$ two recordings with the lowest standard deviation (s.d.) were chosen. The s.d. was calculated from every heartbeat during a period of $8 \mathrm{~s}$. In eight subjects (five females and three males) repeatability tests for $\mathrm{PWV}_{\mathrm{ao}}$ and AIx were performed by the same operator on the same day, with a period of $30 \mathrm{~min}$ between the two measurements.

The algorithm for estimation of central systolic BP (cSBP) has been derived from the relationship between invasively measured CSBP and SBP in the brachial artery, and cSBP estimated by AG correlates well with invasively measured $\mathrm{CSBP}^{18}$

\section{SphygmoCor}

AIx and $\mathrm{PWV}_{\text {ao }}$ were measured using SC equipment connected to a computer with SphygmoCor 2000 software (version 7.01; AtCor Medical). The pulse tracings for $\mathrm{AIx}_{\mathrm{ao}} \mathrm{SC}$ and $\mathrm{PWV}_{\mathrm{ao}} \mathrm{SC}$ calculations were registered with a single high-fidelity tonometer gently pressed to the artery (SPT-301B; Millar Instruments, Houston, TX, USA). The arterial pulse waves were processed by the system software, and the corresponding aortic pressure waveform was generated from the radial artery waveform using a validated transfer factor. ${ }^{19,20}$
The $\mathrm{AIx}_{\mathrm{ao}} \mathrm{SC}$ was defined as the difference between the first (P1) and the second (P2) peaks of the central aortic waveform, expressed as a percentage of pulse pressure, whereas $\mathrm{AIx}_{\mathrm{rd}} \mathrm{SC}$ was defined as (P2 - diastolic BP (DBP))/ (P1-DBP). The transfer time (TT) between pulse arrival at the left CCA and the right femoral artery, calculated by means of the electrocardiogram R-wave as a reference, was used to determine $\mathrm{PWV}_{\mathrm{ao}} \mathrm{SC}$.

A measuring tape established the corresponding distance that the pulse traveled. The jugulum-femoral length was obtained as the jugulum-to-umbilicus plus umbilicus-to-right femoral artery distances. The carotid-jugulum distance is needed to be subtracted from the jugulum-femoral distance because of a compensation for the parallel transmission along the brachiocephalic, carotid arteries and around the aortic arch. ${ }^{21}$ The corrected distance was used for calculating the $\mathrm{PWV}_{\mathrm{ao}}$. Consequently, the length for pulse travel was calculated as jugulum-to-femoral minus jugulum-to-carotid distances $\left(L_{\text {subtracted }}\right)$, and $\mathrm{PWV}_{\mathrm{ao}} \mathrm{SC}=L_{\text {subtracted }} / \mathrm{TT}\left(\mathrm{m} \mathrm{s}^{-1}\right)$. We standardized the subtracted path lengths to direct path lengths. ${ }^{22}$ To achieve this, we applied the following formula to obtain the direct distance $\left(L_{\text {direct }}\right): L_{\text {direct }}(\mathrm{m})=0.45 \times L_{\text {subtracted }}+$ $0.21 \times$ height $+0.08 .{ }^{23}$ Further, as $L_{\text {direct }}$ leads to an overestimation of the real $\mathrm{PWV}_{\mathrm{ao}}$, a scaling factor was used to convert $\mathrm{PWV}_{\mathrm{ao}}$ to 'real' or 'standardized (St)' $\mathrm{PWV}_{\mathrm{ao}}$, where St-PWV $\mathrm{ao}_{\mathrm{a}} \mathrm{SC}\left(\mathrm{m} \mathrm{s}^{-1}\right)=0.8 \times L_{\mathrm{direct}} / \mathrm{TT}^{24,25}$

The $\mathrm{PWV}_{\mathrm{ao}}$ and aortic AIx are presented as mean values from two recordings. The $\mathrm{PWV}_{\mathrm{ao}}$ recordings were chosen from the waveforms with the lowest s.d., and AIx from the waveforms within the limits of the current quality control settings and a quality index above 0.85 . The brachial BP was measured in connection with the examination and is presented as a mean value of two measurements. The radial pulse and transferred aortic blood pulse were calibrated against the brachial SBP and DBP by using an automatic monitor (Omron M7; Omron Healthcare, Kyoto, Japan).

The cSBP was estimated from a transfer function in the SphygmoCor software system..$^{19,20}$ Repeatability for $\mathrm{PWV}_{\mathrm{ao}} \mathrm{SC}$ and $\mathrm{AIx}_{\mathrm{ao}} \mathrm{SC}$ was evaluated in eight subjects (five females and three males) by the same operator, with a period of 30 min between the two measurements.

\section{Ultrasound in the CCA}

Two-dimensional images of the right CCA were acquired by GE Vivid 7 using $12 \mathrm{~L}$ and $7 \mathrm{~L}$ transducers (GE Vingmed Ultrasound AS, Horten, Norway). The two-dimensional recordings of intima-media thickness of the CCA (cIMT) and $\mathrm{M}$-mode registrations were evaluated $1-1.5 \mathrm{~cm}$ proximal to the carotid bulb. At least three diastolic images at the time of the electrocardiogram R-wave were stored digitally on magnet optics discs and Image Vault 5.0 system (GE Vingmed Ultrasound AS) and analyzed using EchoPAC PC version BT 11 (GE Vingmed Ultrasound AS). This validated carotid analyses program identified the boarders of the cIMT automatically. ${ }^{26} \mathrm{~A} 10 \mathrm{~mm}$ long segment was selected in the CCA just proximal to the carotid bulb, and a region of interest was manually placed for detection of cIMT of the far wall. The cIMT was defined as the distance from the leading edge of the lumen-intima interface to the leading edge of the media-adventitia of the far wall. ${ }^{27}$ The mean and maximal values of three cIMT images from the right CCA are reported. The end-diastolic and end-systolic lumen diameters of CCA were measured from the M-mode registration at the Rand T-waves of the concomitant electrocardiogram. The mean values of three lumen diameter measurements were used. The images were analyzed in random order by the same investigator at the end of the study. The cstrain was calculated as the difference between the systolic and diastolic lumen diameter, divided by the diastolic lumen diameter. The stiffness index in CCA $\left(\beta_{\mathrm{CCA}}\right)$ was calculated by the formula: $\beta_{\mathrm{CCA}}=\ln \left(P_{\text {systolic }} / P_{\text {diastolic }}\right) /$ strain. The brachial BP was measured in connection with the M-mode registration, with the cuff placed on the arm with the highest $\mathrm{BP}$.

\section{Systemic vascular resistance and $\mathrm{BP}$}

Systemic vascular resistance $(\mathrm{SVR})\left(\mathrm{mm} \mathrm{Hg} \times \mathrm{min}^{-1}\right)$ was calculated as mean arterial BP $(\mathrm{mm} \mathrm{Hg})$ divided by cardiac output $\left(1 \mathrm{~min}^{-1}\right)$. Arterial BP was measured in both arms, after $30 \mathrm{~min}$ of supine rest, using a digital automatic BP monitor (M7; Omron Healthcare). The mean values of SBP and DBP in both arms were calculated. The arm with the highest BP was used to measure the $\mathrm{BP}$ in connection with the ultrasound registrations of CCA. Mean arterial $\mathrm{BP}$ was calculated as $\mathrm{DBP}+1 / 3 \times(\mathrm{SBP}-\mathrm{DBP})$. 
To calculate stroke volume and cardiac output, the transthoracic Doppler echocardiography was performed in all subjects using Vivid 7 ultrasound equipment (General Electric Company, Horten, Norway). The left ventricular outflow tract diameter was measured in systole from the parasternal long axis view, and the velocity time integral was measured from a pulsed Doppler blood flow recording in left ventricular outflow tract from the apical view. The stroke volume was calculated according to the formula: stroke volume $=\pi \times$ (left ventricular outflow tract diameter $/ 2)^{2} \times$ left ventricular outflow tract velocity time integral, and cardiac output was obtained by multiplying stroke volume by heart rate. The heart rate was measured during the echocardiography examination and the BP was measured at the end of the examination.

\section{Biochemical analyses}

Plasma concentrations of high-sensitivity C-reactive protein, serum concentration of total cholesterol and triglycerides were estimated using Synchron LX 20 system (Beckman Coulter, Brea, CA, USA).

\section{Statistics}

Statistical analyses were performed with Statistica (version 9.0; Statsoft, Tulsa, OK, USA). All data are expressed as mean \pm s.d. The tests were carried out two-tailed and $P<0.05$ was considered to be statistically significant. Spearman's rank correlation coefficients, $r$, were computed to assess relationships between variables. Mann-Whitney $U$-test for unpaired data was used for comparison between genders. Results from the multiple regression analyses were presented as standardized $\beta$ and adjusted $R^{2}$. Wilcoxon's signed rank-sum test was used to test differences between the two devices. Bland-Altman test was used to evaluate the variability between the two techniques. ${ }^{28}$ The coefficient of variation (CV\%), defined as the s.d. of the absolute differences between measurements, divided by the mean of two measurements was used to evaluate variability.

\section{RESULTS}

Clinical and biochemical parameters of the healthy study group, by gender, are shown in Table 1. The mean age of the study group was $48.0 \pm 14.9$ years (range 20-69 years, male $41 \pm 15$ years vs. female $51 \pm 14$ years, $P<0.01)$. The weight, height and SBP were higher in males compared with females. There were no significant differences in plasma high-sensitivity C-reactive protein, serum triglycerides or serum cholesterol between males and females.

\section{Pulse wave velocity}

For calculation of PWV, the surface distance and the traveled time or RT were measured. The surface distance determined for AG/SC correlated (all $P<0.001)$ to age $(-0.57 /-0.39)$, gender $(-0.57 /$ $-0.43)$, weight $(0.62 / 0.62)$ and height $(0.82 / 0.61)$. The surface distance measured for AG $(51.5 \pm 3.2)$ (Figure 1) was significantly higher $(P<0.001)$ than for SC $(46.6 \pm 4.4)$, although well related $(r=0.76, P<0.001)$. No significant differences were observed between $\mathrm{RT} / 2$ and transit time (TT), measured by AG, RT/2 (68.8 \pm 18.0$)$ and SC, TT $(69.8 \pm 14.0)$ (Figure 1$)$, and they correlated well $(r=0.72$, $P<0.001)$. RT/ 2 by AG and TT by SC correlated with age $(r=-0.74 /$ -0.79 , both $P<0.001)$, height $(r=0.55 / 0.49$, both $P<0.001)$ and gender (AG: $r=-0.47, P<0.001$; and SC: $-0.35, P<0.01$ ).

$\mathrm{PWV}_{\mathrm{ao}} \mathrm{AG}\left(8.00 \pm 2.16 \mathrm{~m} \mathrm{~s}^{-1}\right.$, range 5.22-13.89) did not differ from St-PWV $\mathrm{ao}_{\mathrm{ao}} \mathrm{SC}\left(7.68 \pm 1.58 \mathrm{~m} \mathrm{~s}^{-1}\right.$, range $\left.5.18-13.34\right)$, but was significantly higher than $\mathrm{PWV}_{\mathrm{ao}} \mathrm{SC}\left(6.87 \pm 1.47 \mathrm{~m} \mathrm{~s}^{-1}\right.$, range 4.50 12.30, $P<0.001$ ) (Table 2). The Bland-Altman plots in Figure 2 illustrate the agreement for $\mathrm{PWV}_{\mathrm{ao}} \mathrm{AG}$ with $\mathrm{PWV}_{\mathrm{ao}} \mathrm{SC}$ and St$\mathrm{PWV}_{\mathrm{ao}} \mathrm{SC}$, respectively. St-PWV $\mathrm{ao}$ SC $\left(6.78 \pm 0.83 \mathrm{~m} \mathrm{~s}^{-1}\right)$ was found to be higher $(P=0.008)$ than $P W V_{a 0} A G\left(6.37 \pm 0.54 \mathrm{~m} \mathrm{~s}^{-1}\right)$ for values below the median of AG and SC average $\left(7.4 \mathrm{~m} \mathrm{~s}^{-1}\right)$. Above median, differences were more scattered and $\mathrm{PWV}_{\mathrm{ao}} \mathrm{AG}$ $\left(9.62 \pm 1.94 \mathrm{~m} \mathrm{~s}^{-1}\right)$ did not differ significantly from St-PWV $\mathrm{ao}_{\mathrm{o}} \mathrm{SC}$
Table 1 Clinical and biochemical hemodynamic parameters of the study group

\begin{tabular}{|c|c|c|c|}
\hline & $\begin{array}{c}\text { All subjects } \\
\quad(\mathrm{N}=63)\end{array}$ & $\begin{array}{l}\text { Female } \\
(\mathrm{N}=42)\end{array}$ & $\begin{array}{c}\text { Male } \\
(\mathrm{N}=21)\end{array}$ \\
\hline Age (years) & $48.0 \pm 14.9$ & $51.3 \pm 13.7$ & $41.2 \pm 15.2^{* *}$ \\
\hline Weight (kg) & $68.0 \pm 10.6$ & $63.0 \pm 7.3$ & $78.0 \pm 9.2^{* * *}$ \\
\hline Height (m) & $170.9 \pm 9.9$ & $166.0 \pm 7.0$ & $180.9 \pm 6.8^{* * *}$ \\
\hline BMI $\left(\mathrm{kg} \mathrm{m}^{-2}\right)$ & $23.18 \pm 2.32$ & $22.86 \pm 2.24$ & $23.80 \pm 2.40$ \\
\hline HR (b.p.m.) & $60 \pm 9$ & $61 \pm 9$ & $58 \pm 8$ \\
\hline $\mathrm{SBP}(\mathrm{mm} \mathrm{Hg})$ & $118 \pm 13$ & $116 \pm 13$ & $122 \pm 11^{*}$ \\
\hline DPB (mm Hg) & $73 \pm 9$ & $73 \pm 9$ & $74 \pm 7$ \\
\hline MAP (mm Hg) & $88 \pm 9$ & $87 \pm 10$ & $90 \pm 8$ \\
\hline $\mathrm{SV}(\mathrm{ml})$ & $72 \pm 17$ & $67 \pm 12$ & $83 \pm 20 * * *$ \\
\hline $\operatorname{SVR}\left(\mathrm{mm} \mathrm{Hg} \times \min \mathrm{I}^{-1}\right)$ & $21.4 \pm 4.9$ & $22.2 \pm 4.8$ & $19.8 \pm 5.0$ \\
\hline \multicolumn{4}{|l|}{ Biochemical variables } \\
\hline $\begin{array}{l}\text { Serum cholesterol } \\
\left(\mathrm{mmoll}^{-1}\right)\end{array}$ & $5.41 \pm 1.18^{a}$ & $5.49 \pm 1.14^{b}$ & $5.21 \pm 1.29^{c}$ \\
\hline $\begin{array}{l}\text { Serum triglycerides } \\
\left(\mathrm{mmoll}^{-1}\right)\end{array}$ & $0.83 \pm 0.41^{a}$ & $0.77 \pm 0.34^{b}$ & $0.99 \pm 0.53^{c}$ \\
\hline Plasma hs-CRP $\left(\mathrm{mgl}^{-1}\right)$ & $1.02 \pm 1.16^{a}$ & $0.97 \pm 1.23^{b}$ & $1.13 \pm 1.27^{c}$ \\
\hline
\end{tabular}

All parameters are presented as means \pm s.d.

Abbreviations: BMI, body mass index; b.p.m., beats per minute; DBP, diastolic blood pressure; HR, heart rate; hs-CRP, high-sensitivity C-reactive protein; MAP, mean arterial blood pressure;

SBP, systolic blood pressure; SV, stroke volume; SVR, systemic vascular resistance. Statistically significant $P$-value between males and females: ${ }^{*} P<0.05$, ${ }^{* *} P<0.01$ and $* * * P<0.001$.

${ }^{\mathrm{a}} \mathrm{N}=57$.

(

${ }^{\mathrm{c}} N=16$.

$\left(8.58 \pm 1.66 \mathrm{~m} \mathrm{~s}^{-1}\right) . \mathrm{PWV}_{\mathrm{ao}}$ by $\mathrm{SC}$ and AG differed significantly $(P<0.001)$ in females, but not in males $(P=0.40)$ (Figure 3$)$.

The CV \% for $\mathrm{PWV}_{\text {ao }}$ between two registrations within one session were $9.3 \%(n=59)$ for $\mathrm{PWV}_{\mathrm{ao}} \mathrm{AG}$ and $9.6 \%(n=51)$ for $\mathrm{PWV}_{\mathrm{ao}} \mathrm{SC}$. The $\mathrm{CV} \%$ for $\mathrm{PWV}_{\text {ao }}$ between two registrations $30 \mathrm{~min}$ apart $(n=8)$ were $6.8 \%$ for $\mathrm{PWV}_{\mathrm{ao}} \mathrm{SC}$ and $5.9 \%$ for $\mathrm{PWV}_{\mathrm{ao}} \mathrm{AG}$; the Bland-Altman plot of the reproducibility of these measurements is shown in Figure 4. The $\mathrm{PWV}_{\mathrm{ao}}$ of both techniques correlated with each other and to carotid strain, stiffness index and intima-media thickness (cstrain, $\beta_{\mathrm{CCA}}, \mathrm{cIMT}_{\text {mean }}, \mathrm{CIMT}_{\max }$ ), age, $\mathrm{BP}$ and serum cholesterol, but only $\mathrm{PWV}_{\text {ао }}$ by AG to gender, height and weight (Table 3). The distributions of $\mathrm{PWV}_{\mathrm{ao}} \mathrm{SC}$ and $\mathrm{St}-\mathrm{PWV} \mathrm{ao}_{\mathrm{ao}} \mathrm{SC}$ according to age in healthy subjects are shown in Table 4.

Stepwise multiple regression analyses were performed with $\mathrm{PWV}_{\mathrm{ao}}$ as dependent variable and age, gender, SBP, height and weight as independent variables. For $\mathrm{PWV}_{\mathrm{ao}} \mathrm{AG} 38 \%$ of the variation was explained by age $(\beta 0.63, P<0.001)$, for $\mathrm{PWV}_{\mathrm{ao}} \mathrm{SC} 48 \%$ by age ( $\beta$ 0.44, $P<0.001)$ and SBP $(\beta 0.40, P<0.001)$, and finally for St-PWV $\mathrm{ao}_{\mathrm{a}} \mathrm{SC} 52 \%$ was explained by age $(\beta 0.48, P<0.001)$ and SBP $(\beta 0.38, P<0.001)$ (Table 5).

\section{Augmentation index}

AIx $_{\mathrm{ao}}$ by AG and SC were closely correlated, but AG showed significantly higher values $(27.5 \pm 14.5$ vs. $20.5 \pm 17.4 \%, P<0.001)$ (Tables 2 and 3). A Bland-Altman plot illustrates $\mathrm{AIx}_{\mathrm{ao}}$ agreement between AG and SC in Figure 2. Higher $\operatorname{AIx}_{\mathrm{ao}}$ values $(P<0.001)$ were found for AG (14.7 $\pm 7.0 \%)$, compared with SC (5.3 $\pm 11.0 \%)$ below the median of AG and SC average, $27.6 \%$, and also above the median, AG $(39.8 \pm 7.2 \%)$, and SC $(35.2 \pm 6.1 \%)$.

The CV \% for $\mathrm{AIx}_{\mathrm{ao}}$ between two registrations within one session were $11.2 \%(n=57)$ for $\mathrm{AG}$ and $14.8 \%(n=59)$ for SC. 
a Transfer time (TT) by SphygmoCor (SC) and return time (RT/2) by Arteriograph (AG)

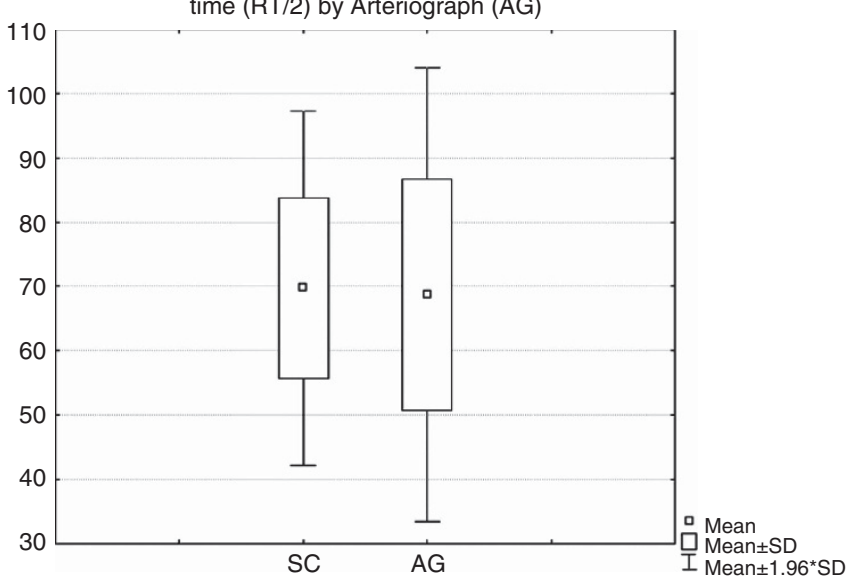

b Surface distance, $\mathrm{cm}$, by ShpygmoCor (SC)

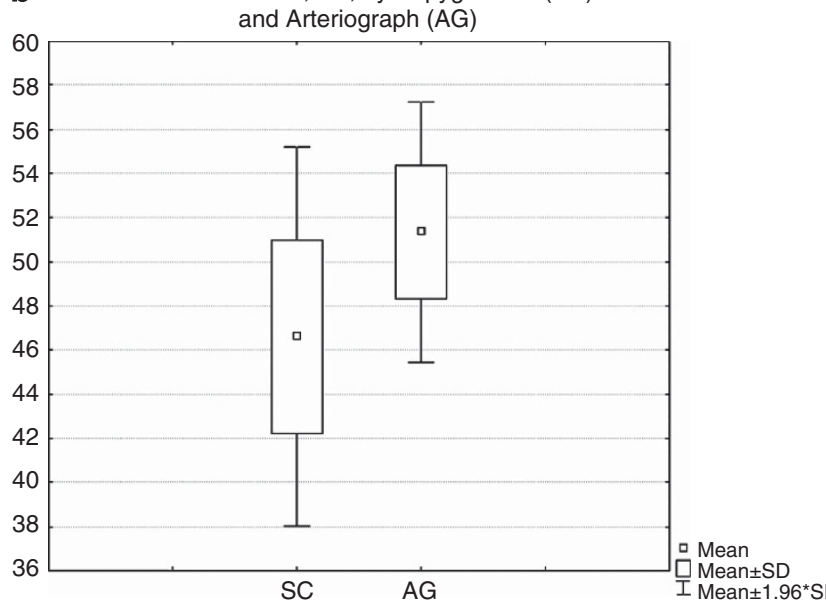

Figure 1 Box-plot comparison of transfer time (TT (mean time difference)) (SphygmoCor (SC)) and return time (RT/2) (Arteriograph (AG)) and surface distance between $S C$ and $A G$. (a) TT (SC and RT/2 (AG). (b) Surface distance (below the figure). No significant differences were observed between SC TT $(69.8 \pm 14.0)$ and AG RT $(68.8 \pm 18.0)$; correlation $r=0.72, P<0.001$. A higher $(P<0.001)$ surface distance was measured by AG $(51.5 \pm 3.15)$ compared with (ordinary) SC $(46.6 \pm 4.4)$; correlation $r=0.76, P<0.001$.

Bland-Altman plots for reproducibility of $\mathrm{AIx}_{\mathrm{ao}}$ repeated $30 \mathrm{~min}$ apart measured by AG and SC $(n=8)$ are shown in Figure 4 . AIx $x_{\mathrm{ao}}$ by AG and SC both correlated significantly with age, gender, SBP, DBP, height, weight, serum cholesterol, $\mathrm{CIMT}_{\text {mean }}, \mathrm{CIMT}_{\max }, \mathrm{cstrain}$ and $\beta_{\mathrm{CCA}}$, Table 3. Only $\mathrm{AIx}_{\mathrm{ao}}$ measured by SC correlated with plasma high-sensitivity C-reactive protein (Table 3 ).

Stepwise regression analyses were performed with $\mathrm{AIx}_{\mathrm{ao}}$ as dependent variable and age, gender, SBP, height and weight as independent variables. For $\mathrm{AIx}_{\mathrm{ao}}$ measured by $\mathrm{AG} 79 \%$ of the variation was explained by age $(\beta 0.72, P<0.001)$, gender $(\beta 0.25 P<0.001)$ and

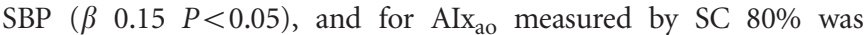
explained by age $(\beta 0.85, P<0.001)$ and gender $(\beta 0.13, P<0.05)$ (Table 5).

\section{BP and SVR}

No significant differences were seen in SBP and DBP measured by AG and Omron M7 (used for SC). Correlations for SBP were: $r=0.79$, $P<0.001$; and for DBP: $r=0.80, P<0.001$. The CV \% between AG
Table 2 Hemodynamic and carotid ultrasound parameters of the study group

\begin{tabular}{|c|c|c|c|}
\hline & $\begin{array}{c}\text { All subjects } \\
\quad(\mathrm{N}=63)\end{array}$ & $\begin{array}{l}\text { Female } \\
(\mathrm{N}=42)\end{array}$ & $\begin{array}{c}\text { Male } \\
(\mathrm{N}=21)\end{array}$ \\
\hline $\mathrm{PWV}_{\mathrm{ao}} \mathrm{SC}\left(\mathrm{ms}^{-1}\right)$ & $6.87 \pm 1.47^{\mathrm{a}}$ & $6.98 \pm 1.57^{\mathrm{b}}$ & $6.64 \pm 1.23^{c}$ \\
\hline St-PWV ${ }_{a o} S C\left(\mathrm{~m} \mathrm{~s}^{-1}\right)$ & $7.68 \pm 1.58^{\mathrm{a}}$ & $7.83 \pm 1.70^{\mathrm{b}}$ & $7.36 \pm 1.28^{c}$ \\
\hline$P W V_{a o} A G\left(m^{-1}\right)$ & $8.00 \pm 2.13^{a}$ & $8.58 \pm 2.30^{b}$ & $6.75 \pm 1.09^{c, * *}$ \\
\hline Alx $x_{r d}$ SC (\%) & $72.5 \pm 23.0$ & $78.6 \pm 21.0$ & $60.2 \pm 22.5^{* *}$ \\
\hline$A l x_{b r} A G(\%)$ & $-12.0 \pm 34.1$ & $-1.2 \pm 31.7$ & $-33.9 \pm 28.3^{* * *}$ \\
\hline Alx $_{\mathrm{ao}} \mathrm{SC}(\%)$ & $20.5 \pm 17.4$ & $25.4 \pm 16.0$ & $10.5 \pm 16.1^{* *}$ \\
\hline $\operatorname{Alx}_{\mathrm{ao}} \mathrm{AG}(\%)$ & $27.5 \pm 14.5$ & $32.0 \pm 13.4$ & $18.2 \pm 12.0^{* * *}$ \\
\hline TT SC (ms) & $69.8 \pm 14.0^{\mathrm{a}}$ & $66.9 \pm 13.6^{b}$ & $76.0 \pm 13.4^{\mathrm{c}, * *}$ \\
\hline $\mathrm{RT} / 2 \mathrm{AG}(\mathrm{ms})$ & $68.8 \pm 18.0^{a}$ & $62.9 \pm 17.3^{b}$ & $81.7 \pm 12.1^{\mathrm{c}, * *}$ \\
\hline Distance SC $(\mathrm{cm})$ & $46.6 \pm 4.4^{\mathrm{a}}$ & $45.5 \pm 4.1^{\mathrm{b}}$ & $49.1 \pm 4.0^{\mathrm{c}, * *}$ \\
\hline Distance AG $(\mathrm{cm})$ & $51.5 \pm 3.2^{\mathrm{a}}$ & $50.2 \pm 2.5^{b}$ & $53.7 \pm 2.6^{\mathrm{c}, * * *}$ \\
\hline $\begin{array}{l}\text { SBP SC/Omron } \\
(\mathrm{mm} \mathrm{Hg})\end{array}$ & $116 \pm 13$ & $115 \pm 14$ & $119 \pm 10$ \\
\hline SBP AG $(\mathrm{mm} \mathrm{Hg})$ & $115 \pm 13$ & $114 \pm 14$ & $118 \pm 11$ \\
\hline $\begin{array}{l}\text { DBP SC/Omron } \\
(\mathrm{mm} \mathrm{Hg})\end{array}$ & $73 \pm 9$ & $72 \pm 9$ & $73 \pm 8$ \\
\hline DBP AG $(\mathrm{mm} \mathrm{Hg})$ & $72 \pm 10$ & $72 \pm 10$ & $73 \pm 9$ \\
\hline PP SC (mm Hg) & $43 \pm 9$ & $42 \pm 9$ & $45 \pm 7$ \\
\hline PP AG $(\mathrm{mm} \mathrm{Hg})$ & $43 \pm 7$ & $42 \pm 7$ & $45 \pm 9$ \\
\hline cSBP SC (mm Hg) & $106 \pm 15$ & $107 \pm 17$ & $106 \pm 12$ \\
\hline cSBP AG (mm Hg) & $112 \pm 17$ & $114 \pm 18$ & $110 \pm 14$ \\
\hline HR SC (b.p.m.) & $56 \pm 7$ & $56 \pm 7$ & $55 \pm 7$ \\
\hline HR AG (b.p.m.) & $56 \pm 8$ & $56 \pm 8$ & $54 \pm 7$ \\
\hline $\mathrm{clMT}_{\text {mean }}(\mathrm{mm})$ & $0.60 \pm 0.14$ & $0.64 \pm 0.14$ & $0.52 \pm 0.09 * *$ \\
\hline $\mathrm{cIMT}_{\max }(\mathrm{mm})$ & $0.73 \pm 0.15$ & $0.77 \pm 0.16$ & $0.65 \pm 0.11^{* * *}$ \\
\hline$c L D_{\min }(\mathrm{cm})$ & $0.59 \pm 0.06$ & $0.57 \pm 0.06$ & $0.62 \pm 0.04^{* * *}$ \\
\hline $\mathrm{cLD}_{\max }(\mathrm{cm})$ & $0.65 \pm 0.06$ & $0.63 \pm 0.06$ & $0.70 \pm 0.04^{* * *}$ \\
\hline cStrain & $0.11 \pm 0.03$ & $0.10 \pm 0.03$ & $0.12 \pm 0.04$ \\
\hline$\beta_{\mathrm{CCA}}$ & $4.95 \pm 1.50$ & $5.11 \pm 1.56$ & $4.61 \pm 8.4$ \\
\hline
\end{tabular}

Abbreviations: AG, Arteriograph; Alx, augmentation index; $\beta_{\mathrm{CCA}}$, carotid stiffness index; b.p.m., beats per minute; cIMT, carotid intima-media thickness; CLD, carotid lumen diameter; cSBP, central systolic blood pressure; DBP, diastolic blood pressure; HR, heart rate; PP, pulse pressure; PWV, pulse wave velocity; RT, return time; SBP, systolic blood pressure; SC, SphygmoCor; TT, transit time.

All parameters are presented as mean $\pm \mathrm{s}$.

Statistically significant $P$-value between males and females: ${ }^{*} P<0.05,{ }^{*} P<0.01$ and $* * * P<0.001$.

${ }^{a} N=60$.

${ }^{\mathrm{b}} \mathrm{N}=41$.

$N=19$

and Omron M7 were $6.7 \%$ for SBP and $8.1 \%$ for DBP. The cSBP values by the two methods were well correlated $(r=0.88, P<0.001)$; however, significantly higher values were obtained by AG $(112 \pm 17 \mathrm{~mm} \mathrm{Hg})$ than SC $(106 \pm 15 \mathrm{~mm} \mathrm{Hg}), P<0.001$. Of the AIx and $\mathrm{PWV}_{\mathrm{ao}}$ measures, only $\mathrm{AIx}_{\mathrm{ao}}$ AG correlated significantly with SVR $(r=0.27, P<0.05)$ (Table 3).

\section{Ultrasound in the CCA}

Carotid $\mathrm{IMT}_{\text {mean }}(r=0.75)$, $\mathrm{cIMT}_{\text {max }}(r=0.72)$, cstrain $(r=-0.60)$ and $\beta_{\mathrm{CCA}}(r=0.61)$ were all related to age $(P<0.001)$. Carotid $\mathrm{IMT}_{\text {mean }}(r=0.57, P<0.001)$, cstrain $(r=-0.41, P<0.01)$ and $\beta_{\mathrm{CCA}}$ $(r=0.39, P<0.01)$ was correlated with serum cholesterol; only cstrain correlated with plasma high-sensitivity C-reactive protein $(r=-0.28$, $P<0.05)$.

\section{DISCUSSION}

Here we explored the relationship between AIx and PWV obtained by $\mathrm{SC}$ and AG, respectively, for the first time in healthy subjects. AIx and 

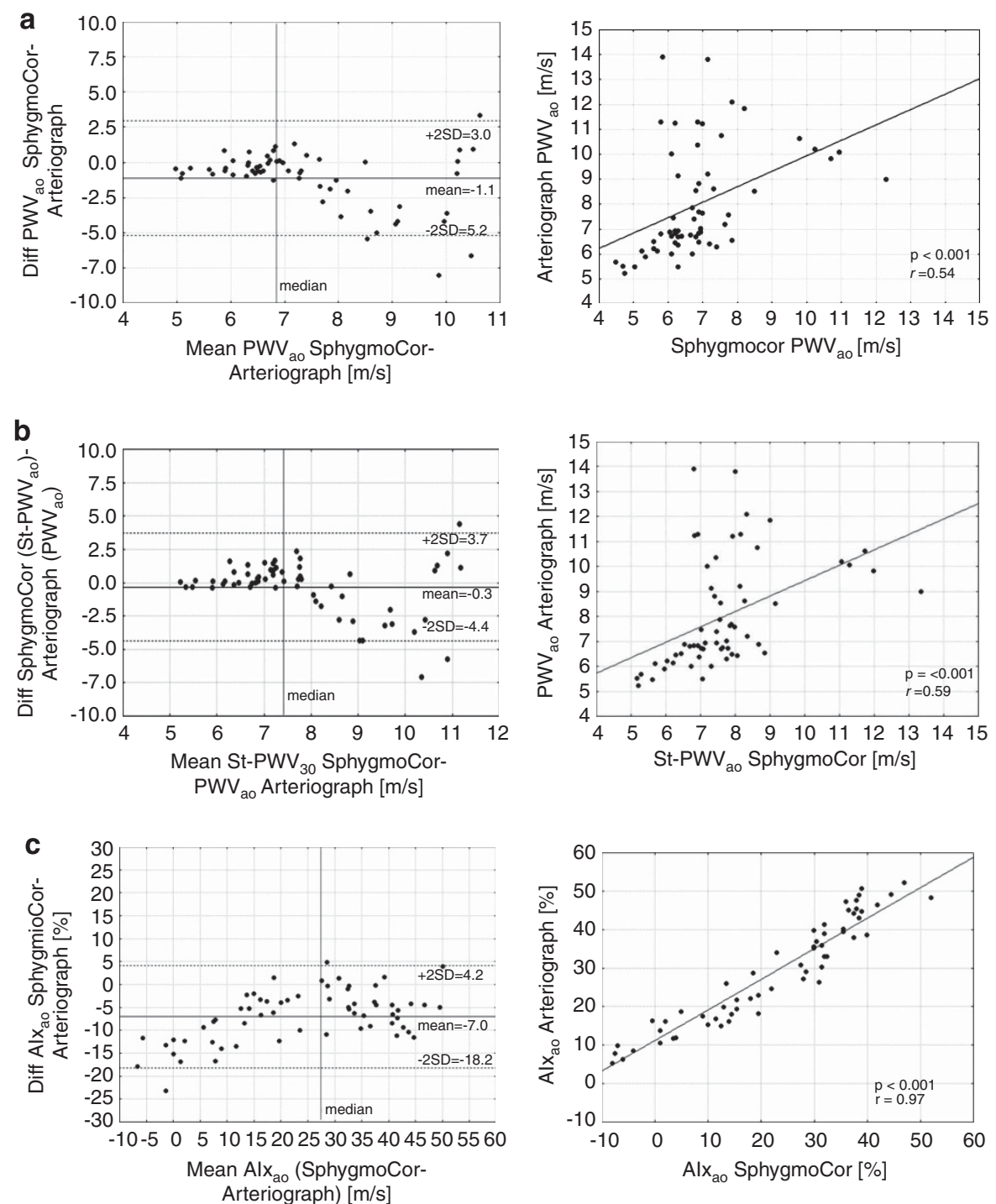

Figure 2 Bland-Altman plot testing the agreement between SphygmoCor (SC) and Arteriograph (AG) for aortic pulse wave velocity (PWV $\mathrm{V}_{0}$ ) and augmentation index $\left(A \mid x_{a 0}\right)$. (a) $\mathrm{PWV}_{\mathrm{ao}} \mathrm{SC}$ and $\mathrm{PWV}_{\mathrm{ao}} \mathrm{AG}$; (b) standardized aortic pulse wave velocity $\left(\mathrm{St}-\mathrm{PWV} \mathrm{v}_{\mathrm{a} o}\right) \mathrm{SC}$ and $\mathrm{PWV} \mathrm{V}_{\mathrm{ao}} \mathrm{AG}$; and (c) $A\left(x_{\mathrm{ao}} \mathrm{SC}\right.$ and $\mathrm{Alx}_{\mathrm{ao}} \mathrm{AG}$.

PWV reflect changes in arterial stiffness, where AIx is considered to be a parameter of wave reflection and reflection site, and PWV provides information about the stiffness of the examined arterial segment. ${ }^{8}$ High correlations in AIx and $\mathrm{PWV}_{\text {ao }}$ measured by AG and SC have been reported in patients with hypertension or other $\mathrm{CV}$ diseases. ${ }^{13-16}$ In our study, we found that the healthy subjects had excellent correlations between $\mathrm{AIx}_{\mathrm{ao}}$ measured by the two devices; and for $\mathrm{PWV}_{\mathrm{ao}}$ there were significant, although not as high, correlations. Bland-Altman illustration of $\mathrm{PWV}_{\mathrm{ao}}$ measurements shows in the lower range little difference between methods, whereas in the upper range there is a scatter. Similar discrepancies for higher $\mathrm{PWV}_{\mathrm{a}}$ can be noted in publications involving patients with CV disease, although the phenomenon has not been emphasized..$^{13,14,29}$ Interestingly, in our study the large scatter for PWV $>7-8 \mathrm{~m} \mathrm{~s}^{-1}$ was mainly shown among females (Bland-Altman plot; Figure 3a). If discrepancies depend on different ways of calculating the TT for the two techniques, it should affect men and women equally. Measures of the surface distance may be a more plausible explanation for a gender discrepancy. In females with large discrepancies in PWV, the RT/TT was mostly lower in AG in comparison with SC. Although mean TT by SC and RT by AG did not differ for the whole group (Figure 1a), the range for RT by AG was wider. It has been shown that the AG has less variation with repeated measures than Complior and SC, and also that it has particular limitations such as sensitivity for position of the cuff. ${ }^{13}$ The measurement of aortic length is also an important factor (see detailed discussion below). However, we have closely followed recommendations for measurements, ${ }^{30}$ including avoiding influence of body contour on estimated aortic length. PWV is increasing with age as a consequence of increased aortic stiffness. With aging the aorta is to a variable degree increasing in length, and underestimation of aortic length could have an opposite effect on PWV estimates, not possible to take into account without using imaging techniques. However, most of the aortic lengthening involves the ascending aorta, which is not included in the arterial length measurement. ${ }^{24}$ Thus, the reason for a wider scatter with higher PWV values is not quite clear.

Values of $\mathrm{AIx}_{\mathrm{a}}$ and $\mathrm{PWV}_{\mathrm{ao}}$ obtained by $\mathrm{AG}$ were significantly higher than by SC. When we standardized $\mathrm{PWV}_{\mathrm{ao}}$ measured by SC 

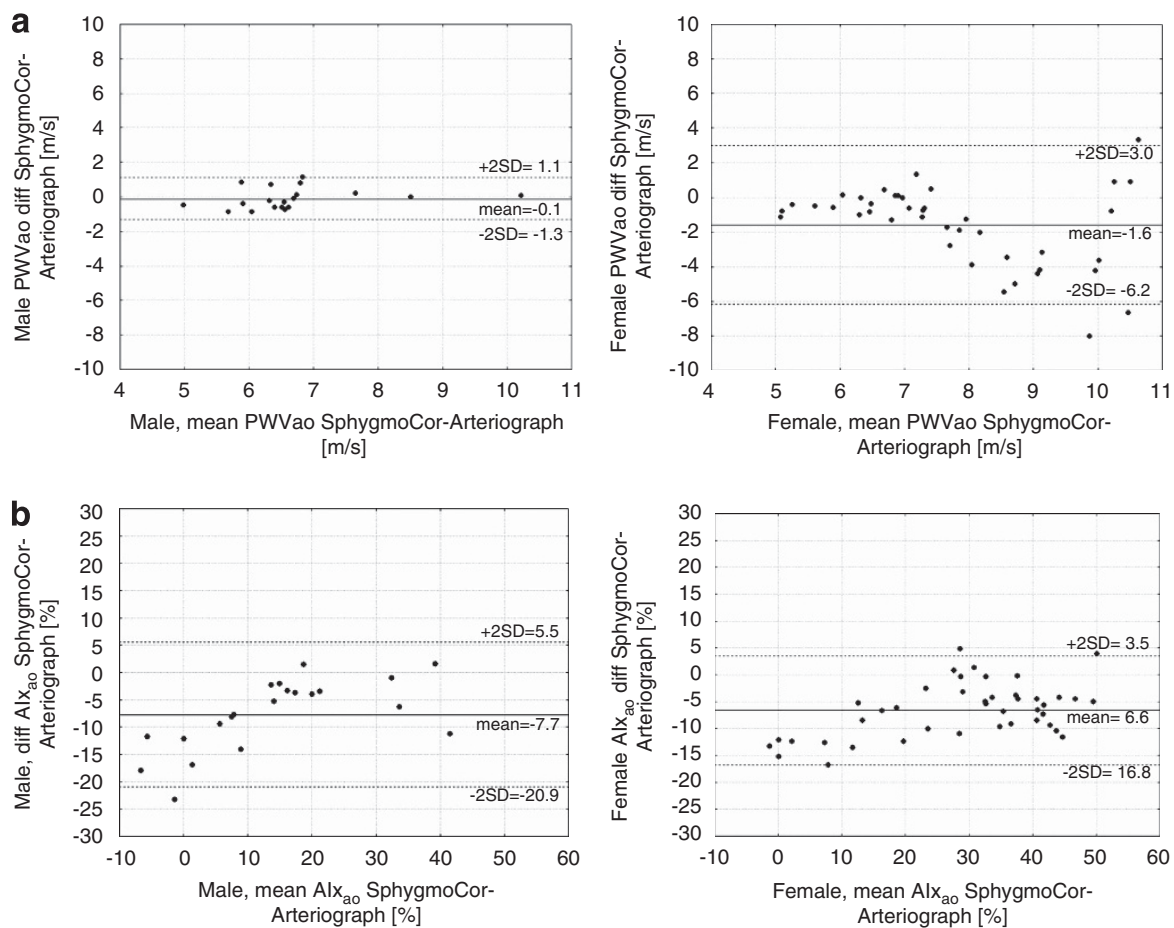

Figure 3 Bland-Altman plots illustrating SphygmoCor (SC) and Arteriograph (AG) measurements in 21 males and 42 females: (a) aortic pulse wave velocity $\left(\mathrm{PWV}_{\mathrm{ao}}\right)$ and $(\mathrm{b})$ augmentation index $\left(\mathrm{Al} \mathrm{x}_{\mathrm{ao}}\right)$.
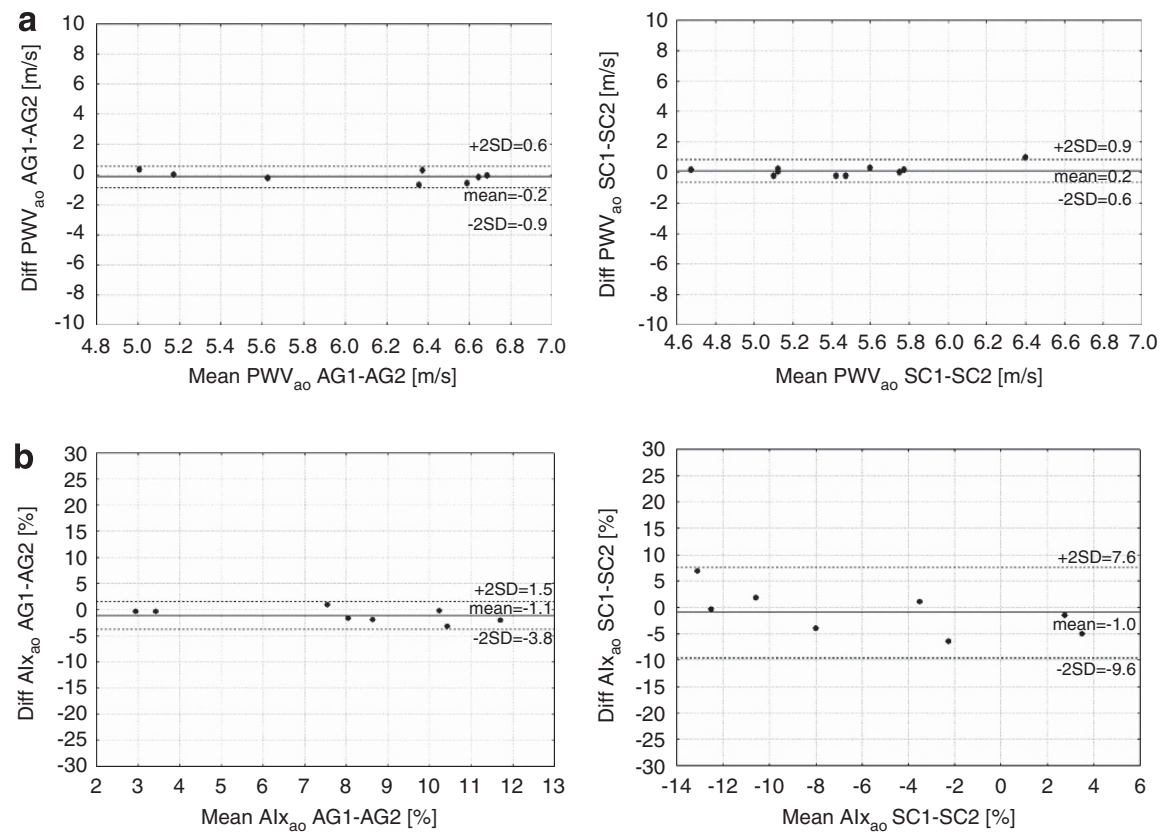

Figure 4 Bland-Altman plots demonstrating the reproducibility of repeated measurements by SphygmoCor (SC) and Arteriograph (AG) in three males and five females: (a) aortic pulse wave velocity $\left(\mathrm{PWV}_{\mathrm{ao}}\right)$ and $(\mathbf{b})$ augmentation index $\left(\mathrm{Al} \mathrm{x}_{\mathrm{ao}}\right)$.

with the formula of directly measured distance CA-FA, ${ }^{22}$ we found no significant differences between SC and AG for the whole group as the use of St-PWV $\mathrm{ao}_{\mathrm{a}} \mathrm{SC}$ increases SC values. However, St-PWV $\mathrm{ao}_{\mathrm{ao}} \mathrm{SC}$ values in the lower range (below the median of $\mathrm{AG}$ and $\mathrm{SC}, 7.4 \mathrm{~m} \mathrm{~s}^{-1}$ ) were higher than $\mathrm{AG}$ values, whereas $\mathrm{PWV}_{\mathrm{ao}} \mathrm{SC}$ and $\mathrm{PWV}_{\mathrm{ao}} \mathrm{AG}$ corresponded well at this level. Thus, although application of the standardized $\mathrm{PWV}_{\mathrm{ao}} \mathrm{SC}$ may make average $\mathrm{PWV}_{\mathrm{ao}}$ values of SC and
AG for a whole group of subjects more similar, it does not on an individual basis correct for the discrepancies between the two methods in the upper range, and less comparable in the lower range.

In the Bland-Altman plot for $\mathrm{AIx}_{\mathrm{ao}}$ lower values for SC concerning the mean of difference were noted overall, but particularly in the lower range, in accordance with previously reported findings. ${ }^{16}$ 
Table 3 Spearman's rank order correlations between pulse wave velocity and augmentation index measured with Arteriograph and SphygmoCor

\begin{tabular}{|c|c|c|c|c|c|}
\hline$N=60-63$ & $A / x_{a o} A G$ & $A l x_{a o} S C$ & $P W V_{a o} A G$ & $P W V_{a o} S C$ & St-PWV ${ }_{a o} S C$ \\
\hline$A \mid x_{a 0} A G(\%)$ & - & $0.97 * * *$ & $0.83^{* * *}$ & $0.51^{* * *}$ & $0.59 * * *$ \\
\hline $\mathrm{Alx}_{\mathrm{ao}} \mathrm{SC}(\%)$ & $0.97 * * *$ & - & $0.82 * * *$ & $0.52 * * *$ & $0.60 * * *$ \\
\hline$P W V_{a o} A G\left(m s^{-1}\right)$ & $0.83^{* * *}$ & $0.82^{* * *}$ & - & $0.54^{* * *}$ & $0.59 * * *$ \\
\hline $\mathrm{PWV}_{\mathrm{ao}} \mathrm{SC}\left(\mathrm{ms}^{-1}\right)$ & $0.51^{* * *}$ & $0.52^{* * *}$ & $0.54^{* * *}$ & - & $0.94^{* * *}$ \\
\hline St-PWV $\mathrm{ao}_{\mathrm{o}} \mathrm{SC}\left(\mathrm{ms}^{-1}\right)$ & $0.59 * * *$ & $0.60 * * *$ & $0.59 * * *$ & $0.94 * * *$ & - \\
\hline $\mathrm{clMT}_{\text {mean }}(\mathrm{mm})$ & $0.68^{* * *}$ & $0.67 * * *$ & $0.59 * * *$ & $0.55^{* * *}$ & $0.58 * * *$ \\
\hline $\mathrm{clMT}_{\max }(\mathrm{mm})$ & $0.60^{* * *}$ & $0.58^{* * *}$ & $0.55^{* * *}$ & $0.61^{* * *}$ & $0.61^{* * *}$ \\
\hline cStrain & $-0.54^{* * *}$ & $-0.55^{* * *}$ & $-0.42^{* *}$ & $-0.45^{* * *}$ & $-0.43^{* *}$ \\
\hline$\beta_{\mathrm{CCA}}$ & $0.49 * * *$ & $0.49 * * *$ & $0.34 * *$ & $0.34 * *$ & $0.34 * *$ \\
\hline Age (years) & $0.87^{* * *}$ & $0.87 * * *$ & $0.67 * * *$ & $0.64 * * *$ & $0.69 * * *$ \\
\hline Gender & $0.45^{* * *}$ & $0.39 * *$ & $0.37 * *$ & 0.12 & 0.14 \\
\hline Height (cm) & $-0.56^{* * *}$ & $-0.52 * * *$ & $-0.39 * *$ & -0.22 & -0.21 \\
\hline Weight (kg) & $-0.34^{* *}$ & $-0.33^{* *}$ & $-0.25^{*}$ & -0.06 & -0.13 \\
\hline $\mathrm{SBP}(\mathrm{mm} \mathrm{Hg})$ & $0.35^{* *}$ & $0.36 * *$ & $0.34 * *$ & $0.36 * *$ & $0.38 *$ \\
\hline DBP (mm Hg) & $0.54^{* * *}$ & $0.53^{* *}$ & $0.49 * * *$ & $0.51 * * *$ & $0.50 * *$ \\
\hline MAP (mm Hg) & $0.47^{* * *}$ & $0.47 * * *$ & $0.45^{* * *}$ & $0.46 * * *$ & $0.47 * *$ \\
\hline SVR $\left(\mathrm{mm} \mathrm{Hg} \times \mathrm{min}^{-1}\right)$ & $0.27^{*}$ & 0.22 & 0.15 & $-0.02^{a}$ & $-0.04^{a}$ \\
\hline Plasma hs-CRP $\left(\mathrm{mgl}^{-1}\right)$ & $0.24^{\mathrm{a}}$ & $0.30^{\mathrm{a}, *}$ & $0.20^{\mathrm{a}}$ & $0.12^{b}$ & $0.16^{\mathrm{b}}$ \\
\hline Serum cholesterol (mmoll-1) & $0.58^{\mathrm{a}, * * *}$ & $0.57^{a, * * *}$ & $0.47^{a, * * *}$ & $0.54^{\mathrm{b}, * * *}$ & $0.55^{\mathrm{b}, * * *}$ \\
\hline Serum triglycerides $\left(\mathrm{mmol}^{-1}\right)$ & $-0.09^{a}$ & $-0.14^{a}$ & $-0.12^{\mathrm{a}}$ & $0.23^{b}$ & $0.23^{b}$ \\
\hline
\end{tabular}

Table 4 Distribution of $\mathrm{PWV}_{\mathrm{ao}}$ according to age in healthy subjects

\begin{tabular}{lrccc} 
Age (years) & $\mathrm{N}=60$ & $P W V_{a o} S C\left(m s^{-1}\right)$ & $S t-P W V_{a o} S C\left(m s^{-1}\right)$ & $P W V_{a 0} A G\left(m s^{-1}\right)$ \\
\hline $20-30$ & 14 & $5.7 \pm 0.7$ & $6.4 \pm 0.8$ & $6.2 \pm 0.6$ \\
$31-40$ & 3 & $5.9 \pm 1.3$ & $5.3 \pm 1.3$ & $6.7 \pm 1.0$ \\
$41-50$ & 11 & $6.7 \pm 0.5$ & $7.3 \pm 0.6$ & $7.1 \pm 1.2$ \\
$51-60$ & 19 & $6.8 \pm 0.7$ & $7.7 \pm 0.6$ & $8.9 \pm 2.2$ \\
$61-70$ & 13 & $8.5 \pm 2.0$ & $9.6 \pm 2.0$ & $9.7 \pm 2.1$ \\
\hline
\end{tabular}

Abbreviations: $\mathrm{PWV} \mathrm{a}_{\mathrm{a}} \mathrm{AG}$, aortic pulse wave velocity by Arteriograph; $\mathrm{PWV}_{\mathrm{ao}} \mathrm{SC}$, aortic pulse wave velocity by SphygmoCor; $\mathrm{St}-\mathrm{PWV}{ }_{\mathrm{a} o \mathrm{~S}} \mathrm{SC}$, standardized aortic pulse wave velocity by SphygmoCor.

The AIx is a measure of composite vascular function, including not only static properties such as distensibility but also dynamic ones such as endothelial function and the peripheral resistance. ${ }^{31,32}$ Both AG and SC have recently been validated invasively. Horváth et al. ${ }^{18}$ validated $\mathrm{AG}$, measuring $\mathrm{AIx}, \mathrm{PWV}_{\mathrm{ao}}$ and the $\mathrm{cSBP}$, and found strong correlations between the invasively measured aortic AIx and brachial AIx obtained noninvasively by AG.

In the present study, cSBP estimated by SC was lower in comparison with cSBP by AG, which is consistent with earlier results. ${ }^{16}$ This may be explained by a difference in the assessment of cSBP by the two devices. SC calibrates the radial pulse wave by the brachial BP, whereas AG calibrates the brachial pulse wave with brachial BP. Furthermore, the cSBP SC is estimated by an intrinsic transfer function in the SC software. ${ }^{19,20}$ The AG system calculates cSBP by an algorithm based on the empiric correlation between the late systolic shoulder point of the systolic augmentation in the brachial pulse wave ${ }^{32,33}$ and cSBP derived from invasive studies. ${ }^{18,16}$ By using an alternative formula for SC to calculate mean arterial pressure $(\mathrm{DBP}+0.4 \times \mathrm{PP})$, with a constant of 0.4 instead of 0.33 , may reduce the differences between $\mathrm{SC}$ and $\mathrm{AG} .{ }^{33,16}$
The observed discrepancies of the $\mathrm{PWV}_{\mathrm{ao}}$ values between $\mathrm{AG}$ and SC could possibly be explained by the software algorithms for calculation of the RT (AG) and TT (SC), and/or the differences in measuring the surface distance. A shorter surface distance was measured for the SC method than with AG. However, the traveled times RT/2 (for AG) and TT (for SC) showed no significant differences, as reported previously. ${ }^{14}$ Different surface measurements of assumed pulse propagation distance result in substantial variations in PWV values, between 8.3 and $12 \mathrm{~m} \mathrm{~s}^{-1}$, supporting the need to standardize the technique for measurement of carotid-femoral PWV. ${ }^{34}$ Expert consensus from $2012^{35}$ requests a standardization of the measurement technique on the traveled distance, and recommends a formula ${ }^{36}$ using $80 \%$ of the tape measured distance between CA and FA sites. AG measurements correlate with invasive values for $\mathrm{PWV}_{\mathrm{ao}}$ and $\mathrm{CSBP}^{18}$ For both invasive and noninvasive measurements, the surface distance was measured as jugulumsymphysis. Weber et al. ${ }^{25}$ studied 135 patients, and compared $\mathrm{PWV}_{\mathrm{ao}}$ invasively and noninvasively with SC. They found the method of estimating the travel distance on body surface critical. The best agreement between invasively measured $\mathrm{PWV}_{\mathrm{ao}}$ and noninvasive $\mathrm{PWV}_{\text {ao }}$ SC was obtained when subtracting carotidsuprasternal notch distance from suprasternal notch-femoral distance. Traveled distance measurements are of importance and have been studied noninvasively by Huybrechts et al. ${ }^{36}$ They standardized and validated the methodology for traveled distance measurements in 98 healthy adults between 20 and 79 years. The reference distance was compared with 11 estimates of aortic path length from body surface distance, commonly used in PWV measurements. They found that tape measured distance between the CCA and the common femoral artery from (CA-FA) multiplied by 0.8 corresponds best to the real traveled aortic path length (traveled distance) reconstructed from magnetic resonance imaging. An age-associated elongation of the 
Table 5 Stepwise regression analyses were performed with $\mathrm{PWV}_{\mathrm{ao}}$ and $\mathrm{Alx}_{\mathrm{ao}}$ each time as dependent variables, and age, gender, SBP, height and weight as independent variables

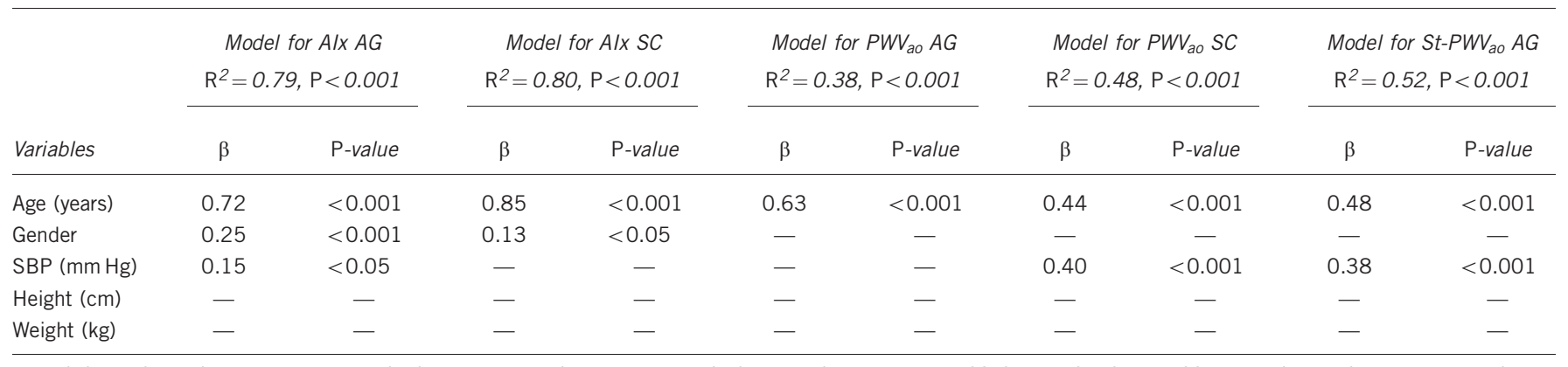

Abbreviations: AG, Arteriograph; Alx, augmentation index; $\mathrm{PWV}_{\mathrm{ao}}$, aortic pulse wave velocity; $\mathrm{SBP}$, systolic blood pressure; SC, $\mathrm{SphygmoCor;}$ St-PWV ${ }_{\mathrm{ao}} \mathrm{SC}$, standardized aortic pulse wave velocity.

aortic path length was observed in their population. Different theories about the true reflection site have been advocated. In a model, Westerhof et al. ${ }^{37}$ showed that the forward and backward waves in the distal aorta are not in phase and concluded that PWV cannot be calculated from time of return of the reflected wave. The major reflection sites may be located at arterial junctions and arteriolar terminations. The distance to a reflecting site, therefore, seems to depend on the vascular distribution of reflection sites rather than a single anatomic site. ${ }^{38,39}$ The major average reflection site does not change with age until 65 years of age, whereas after 65 years of age such change is more pronounced in men than in women. ${ }^{40} \mathrm{~A}$ combination of arterial waveform analyses and three-dimensional magnetic resonance imaging, in most cases (70\%), indicates that the major effective arterial pressure reflection sites are located between the aortic bifurcation and femoral artery measurements site. ${ }^{40}$

Atherosclerosis is a widespread disease, affecting not only one target organ or territory but also to some degree the whole vascular tree. The carotid artery is a universally accepted denominator and risk indicator for an individual's propensity to suffer from future CV events. Specifically, carotid artery IMT, as well as carotid artery distensibility and stiffness, are widely used as parameters of functional and structural vascular damage, and they are good indicators of CV risk. ${ }^{8,41}$ Despite a lack of clinically overt CV disease, subjects without any clinical manifestations may also have diversity in vascular engagement, as the atherosclerotic process starts at a very early age. ${ }^{42-44}$ In our study of healthy subjects, we found significant correlations between $\mathrm{AIx}_{\mathrm{ao}}$ and $\mathrm{PWV}_{\mathrm{ao}}$ measured with both devices and locally measured carotid stiffness, $\mathrm{CIMT}_{\text {mean }}, \mathrm{CIMT}_{\max }$, cstrain and $\beta_{\mathrm{CCA}}$. We also found that high serum cholesterol, an important risk factor of atherosclerosis, was related to cIMT, cstrain, $\beta_{\mathrm{CCA}}$, age and to $\mathrm{AIx}_{\mathrm{ao}}$ and $\mathrm{PWV}_{\mathrm{ao}}$ with both methods. Importantly, we found essentially similar correlations for AG and SC to the carotid estimations of arterial aging. Similar associations between cIMT and $\mathrm{PWV}_{\mathrm{ao}}$ have been reported. Koivistoinen et al. ${ }^{45}$ reported that PWV is directly and independently correlated with carotid IMT in older individuals; however, no associations between PWV and IMT in young adults were shown. Oren et al. ${ }^{46}$ suggest that in healthy young adults PWV and carotid IMT reflect two separate entities of subclinical vascular damage. ${ }^{46}$ Further, a positive correlation between cIMT and PWV and AIx has been shown in subjects with and without type 2 diabetes. ${ }^{12}$

The $\mathrm{PWV}_{\mathrm{a}}$ or carotid-femoral PWV is considered as the 'gold standard' for arterial stiffness assessment, ${ }^{8}$ and $12 \mathrm{~m} \mathrm{~s}^{-1}$ was earlier proposed to be the cutoff point indicating an increased risk for $\mathrm{CV}$ events. However, a new consensus recommendation now proposes $10 \mathrm{~m} \mathrm{~s}^{-1}$ as a new standard cutoff point for carotid-femoral PWV, ${ }^{35}$ due to the recommended formula to measure traveled distance.
Reference values for arterial stiffness were recently presented, based on data from 13 different centers in Europe. ${ }^{22}$ These investigators used the formula of directly measured distance CA-FA multiplied by 0.8 to calculate $\mathrm{PWV}_{\mathrm{ao}}$, and reported reference values for $\mathrm{PWV}_{\mathrm{ao}}$ according to age and BP. The distribution of St-PWV $\mathrm{ao}_{\mathrm{a}} \mathrm{SC}$ and $\mathrm{PWV}_{\mathrm{ao}} \mathrm{AG}$ in our study (Table 4) showed similar age-adjusted values as the European reference study of normal subjects. ${ }^{22}$ In our study, the average value of PWV obtained by AG was somewhat more comparable to St$\mathrm{PWV}_{\mathrm{ao}} \mathrm{SC}$ than to $\mathrm{PWV}_{\mathrm{ao}} \mathrm{SC}$ for the whole group of participants. However, the application of the standardization formula caused a discrepancy in the lower range by increasing values of SC, whereas it did not correct the scatter of values in the upper range.

\section{Strengths and limitations}

An important strength of our study is the wide age range of 20-69 years of the healthy subjects investigated. The lack of comparison with invasive methods is a limitation. Further, the number of subjects is relatively small, although usually sufficient for comparison of two techniques. Different relations between the techniques might be obtained in atherosclerotic or hypertensive patients. In patients expressing CV pathology, a larger spread of values can be expected, with a greater chance of finding significant relationships between methods compared with detecting such in normal subjects. However, by investigating subjects without known CV disease, we could demonstrate the degree of relationships not depending on overt disease, which is a strength as it has not been studied in detail. Interestingly, similar differences between the techniques in the upper range of PWV can be found in study populations with CV disease. ${ }^{14,15}$

\section{CONCLUSION}

Arterial stiffness by SC and AG correlates with serum cholesterol, as well as with cIMT, cstrain and $\beta_{\mathrm{CCA}}$ verifying the validity of pulse tracings as risk estimates, even in a healthy population without known $\mathrm{CV}$ disease. $\mathrm{AIx}_{\mathrm{a} o}$ results by $\mathrm{AG}$ and SC are closely interrelated, but higher values are obtained by $\mathrm{AG}$. In the lower range, $\mathrm{PWV}_{\mathrm{ao}}$ values by AG and SC are similar, but differ for higher values. Our results imply the necessity to apply the same technique for follow-up of patients in clinical settings or scientific studies.

\section{CONFLICT OF INTEREST}

The authors declare no conflict of interest.

\section{ACKNOWLEDGEMENTS}

We are most grateful for the valuable comments on the manuscript by Associate Professor Gunnar Nyberg. We also thank Linda Hansson for technical support. 
This study was supported by grants from the Swedish Medical Research Council, the Swedish Heart Lung Foundation, the Stockholm County Council.

1 Laurent S, Boutouyrie P, Asmar R, Gautier I, Laloux B, Guize L, Ducimetiere P, Benetos A. Aortic stiffness is an independent predictor of all-cause and cardiovascular mortality in hypertensive patients. Hypertension 2001; 37: 1236-1241.

2 Weber T, Auer J, O'Rourke MF, Kvas E, Lassnig E, Berent R, Eber B. Arterial stiffness, wave reflections, and the risk of coronary artery disease. Circulation 2004; 109: 184-189.

3 Chirinos JA, Zambrano JP, Chakko S, Veerani A, Schob A, Willens HJ, Perez G, Mendez AJ. Aortic pressure augmentation predicts adverse cardiovascular events in patients with established coronary artery disease. Hypertension 2005; 45: 980-985.

4 Boutouyrie P, Tropeano Al, Asmar R, Gautier I, Benetos A, Lacolley P, Laurent S. Aortic stiffness is an independent predictor of primary coronary events in hypertensive patients: a Longitudinal Study. Hypertension 2002; 39: 10-15.

5 Sutton-Tyrrell K, Najiar SS, Boudreau RM, Venkitachalam L, Kupelian V, Simonsick EM, Havlik R, Lakatta EG, Spurgeon H, Kritchevsky S, Pahor M, Bauer D, Newman A. Elevated aortic pulse wave velocity, a marker of arterial stiffness, predicts cardiovascular events in well-functioning older adults. Circulation 2005; 111: 3384-3390.

6 Willum-Hansen T, Staessen JA, Torp-Pedersen C, Rasmussen S, Thijs L, Ibsen H, Jeppesen J. Prognostic value of aortic pulse wave velocity as index of arterial stiffness in the general population. Circulation 2006; 113: 664-670.

7 Nichols WW, Singh BM. Augmentation index as a measure of peripheral vascular disease state. Curr Opin Cardiol 2002; 17: 543-551.

8 Laurent S, Cockcroft J, Van Bortel L, Boutouyrie P, Giannattasio C, Hayoz D, Pannier B, Vlachopoulos C, Wilkinson I, Struijker-Boudier H. Expert consensus document on arterial stiffness: methodological issues and clinical applications. Eur Heart J 2006, 27: 2588-2605.

9 O'Leary DH, Polak JF, Kronmal RA, Manolio TA, Burke GL, Wolfson SK Jr. Carotidartery intima and media thickness as a risk factor for myocardial infarction and stroke in older adults. Cardiovascular Health Study Collaborative Research Group. N Eng/ J Med 1999; 340: 14-22.

10 Taniwaki H, Kawagishi T, Emoto M, Shoji T, Kanda H, Maekawa K, Nishizawa $Y$, Morii $\mathrm{H}$. Correlation between the intima-media thickness of the carotid artery and aortic pulse-wave velocity in patients with type 2 diabetes. Vessel wall properties in type 2 diabetes. Diabetes Care 1999; 22: 1851-1857.

11 van Popele NM, Grobbee DE, Bots ML, Asmar R, Topouchian J, Reneman RS, Hoeks AP, van der Kuip DA, Hofman A, Witteman JC. Association between arterial stiffness and atherosclerosis: The Rotterdam Study. Stroke 2001; 32: 454-460.

12 Gomez-Marcos MA, Recio-Rodriguez JI, Patino-Alonso MC, Agudo-Conde C, GomezSanchez L, Rodriguez-Sanchez E, Martin-Cantera C, Garcia-Ortiz L. Relationship between intima-media thickness of the common carotid artery and arterial stiffness in subjects with and without type 2 diabetes: a case-series report. Cardiovasc Diabetol 2011; 10: 3.

13 Baulmann J, Schillings U, Rickert S, Uen S, Dusing R, Illyes M, Cziraki A, Nickering G, Mengden T. A new oscillometric method for assessment of arterial stiffness: comparison with tonometric and piezo-electronic methods. J Hypertens 2008; 26: 523-528.

14 Rajzer MW, Wojciechowska W, Klocek M, Palka I, Brzozowska-Kiszka M, KaweckaJaszcz K. Comparison of aortic pulse wave velocity measured by three techniques: Complior, sphygmocor and arteriograph. J Hypertens 2008; 26: 2001-2007.

15 Jatoi NA, Mahmud A, Bennett K, Feely J. Assessment of arterial stiffness in hypertension: comparison of oscillometric (arteriograph), piezoelectronic (complior) and tonometric (sphygmocor) techniques. J Hypertens 2009; 27: 2186-2191.

16 Rezai MR, Goudot G, Winters C, Finn JD, Wu FC, Cruickshank JK. Calibration mode influences central blood pressure differences between sphygmocor and two newer devices, the arteriograph and omron hem-9000. Hypertens Res 2011; 34: 1046-1051.

17 Nemeth Z, Moczar K, Deak G. Evaluation of the tensioday ambulatory blood pressure monitor according to the protocols of the British Hypertension Society and the association for the advancement of medical instrumentation. Blood Press Monit 2002; 7: 191-197.

18 Horváth IG, Nemeth A, Lenkey Z, Alessandri N, Tufano F, Kis P, Gaszner B, Cziraki A. Invasive validation of a new oscillometric device (arteriograph) for measuring augmentation index, central blood pressure and aortic pulse wave velocity. $J$ Hypertens 2010; 28: 2068-2075.

19 Karamanoglu M, O'Rourke MF, Avolio AP, Kelly RP. An analysis of the relationship between central aortic and peripheral upper limb pressure waves in man. Eur Heart $J$ 1993; 14: 160-167.

20 Pauca AL, O'Rourke MF, Kon ND. Prospective evaluation of a method for estimating ascending aortic pressure from the radial artery pressure waveform. Hypertension 2001; 38: 932-937.

21 Mitchell GF, Izzo JL Jr, Lacourciere Y, Ouellet JP, Neutel J, Qian C, Kerwin LJ, Block AJ, Pfeffer MA. Omapatrilat reduces pulse pressure and proximal aortic stiffness in patients with systolic hypertension: results of the conduit hemodynamics of omapatrilat international research study. Circulation 2002; 105: 2955-2961.

22 Reference Values for Arterial Stiffness' Collaboration. Determinants of pulse wave velocity in healthy people and in the presence of cardiovascular risk factors: 'Establishing normal and reference values'. Eur Heart J 2010; 31: 2338-2350.

23 Vermeersch SJ, Rietzschel ER, De Buyzere ML, Van Bortel LM, Gillebert TC, Verdonck PR, Laurent S, Segers P, Boutouyrie P. Distance measurements for the assessment of carotid to femoral pulse wave velocity. J Hypertens 2009; 27: 2377-2385.
24 Sugawara J, Hayashi K, Yokoi T, Tanaka H. Age-associated elongation of the ascending aorta in adults. JACC Cardiovasc Imag 2008; 1: 739-748.

25 Weber T, Ammer M, Rammer M, Adji A, O'Rourke MF, Wassertheurer S, Rosenkranz S, Eber B. Noninvasive determination of carotid-femoral pulse wave velocity depends critically on assessment of travel distance: a comparison with invasive measurement. J Hypertens 2009; 27: 1624-1630.

26 Vermeersch SJ, Rietzschel ER, De Buyzere ML, Van Bortel LM, D'Asseler $Y$, Gillebert TC, Verdonck PR, Segers P. Validation of a new automated imt measurement algorithm. J Hum Hypertens 2007; 21: 976-978.

27 Wendelhag I, Gustavsson T, Suurkula M, Berglund G, Wikstrand J. Ultrasound measurement of wall thickness in the carotid artery: fundamental principles and description of a computerized analysing system. Clin Physiol 1991; 11: 565-577.

28 Bland JM, Altman DG. Statistical methods for assessing agreement between two methods of clinical measurement. Lancet 1986; 1: 307-310.

29 Nurnberger J, Michalski R, Turk TR, Opazo Saez A, Witzke O, Kribben A. Can arterial stiffness parameters be measured in the sitting position? Hypertens Res 2011; 34: 202-208.

30 Tomlinson LA. Methods for assessing arterial stiffness: Technical considerations. Curr Opin Nephrol Hypertens 2012; 21: 655-660.

31 Wilkinson IB, Hall IR, MacCallum H, Mackenzie IS, McEniery CM, van der Arend BJ, Shu YE, MacKay LS, Webb DJ, Cockcroft JR. Pulse-wave analysis: clinical evaluation of a noninvasive, widely applicable method for assessing endothelial function. Arterioscler Thromb Vasc Biol 2002; 22: 147-152.

32 Goto T, Ohte N, Fukuta H, Wakami K, Tani T, Kimura G. Relationship between effective arterial elastance, total vascular resistance, and augmentation index at the ascending aorta and left ventricular diastolic function in older women. Circ J 2012; 77: 123-129.

33 Bos WJ, Verrij E, Vincent HH, Westerhof BE, Parati G, van Montfrans GA. How to assess mean blood pressure properly at the brachial artery level. J Hypertens 2007. 25: 751-755.

34 Sugawara J, Hayashi K, Yokoi T, Tanaka H. Carotid-femoral pulse wave velocity: impact of different arterial path length measurements. Artery Res 2010; 4: 27-31.

35 Van Bortel LM, Laurent S, Boutouyrie P, Chowienczyk P, Cruickshank JK, De Backer T, Filipovsky J, Huybrechts S, Mattace-Raso FU, Protogerou AD, Schillaci G, Segers P, Vermeersch S, Weber T. Expert consensus document on the measurement of aortic stiffness in daily practice using carotid-femoral pulse wave velocity. J Hypertens 2012; 30: 445-448.

36 Huybrechts SA, Devos DG, Vermeersch SJ, Mahieu D, Achten E, de Backer TL, Segers P, van Bortel LM. Carotid to femoral pulse wave velocity: a comparison of real travelled aortic path lengths determined by MRI and superficial measurements. J Hypertens 2011; 29: 1577-1582.

37 Westerhof BE, van den Wijngaard JP, Murgo JP, Westerhof N. Location of a reflection site is elusive: consequences for the calculation of aortic pulse wave velocity. Hypertension 2008; 52: 478-483.

38 Taylor MG. Wave transmission through an assembly of randomly branching elastic tubes. Biophys J 1966; 6: 697-716.

39 Nichols WW, O'Rourke MF. Aortic pulse wave velocity, reflection site distance, and augmentation index. Hypertension 2009; 53: e9. author reply e10.

40 Sugawara J, Hayashi K, Tanaka H. Distal shift of arterial pressure wave reflection sites with aging. Hypertension 2010; 56: 920-925.

41 Bots ML, Dijk JM, Oren A, Grobbee DE. Carotid intima-media thickness, arterial stiffness and risk of cardiovascular disease: current evidence. J Hypertens 2002; 20: 2317-2325.

42 McGill HC Jr, McMahan CA, Herderick EE, Malcom GT, Tracy RE, Strong JP. Origin of atherosclerosis in childhood and adolescence. Am J Clin Nutr 2000; 72: 1307S-1315S.

43 Oren A, Vos LE, Uiterwaal CS, Grobbee DE, Bots ML. Cardiovascular risk factors and increased carotid intima-media thickness in healthy young adults: The Atherosclerosis Risk in Young Adults (ARYA) Study. Arch Intern Med 2003; 163: 1787-1792.

44 Hidvegi EV, Illyes M, Benczur B, Bocskei RM, Ratgeber L, Lenkey Z, Molnar FT, Cziraki A. Reference values of aortic pulse wave velocity in a large healthy population aged between 3 and 18 years. J Hypertens 2012; 30: 2314-2321.

45 Koivistoinen $T$, Virtanen M, Hutri-Kahonen N, Lehtimaki T, Jula A, Juonala M, Moilanen L, Aatola H, Hyttinen J, Viikari JS, Raitakari OT, Kahonen M. Arterial pulse wave velocity in relation to carotid intima-media thickness, brachial flow-mediated dilation and carotid artery distensibility: The Cardiovascular Risk in Young Finns Study and the Health 2000 Survey. Atherosclerosis 2012; 220: 387-393.

46 Oren A, Vos LE, Uiterwaal CS, Grobbee DE, Bots ML. Aortic stiffness and carotid intima-media thickness: two independent markers of subclinical vascular damage in young adults? Eur J Clin Invest 2003; 33: 949-954.

(c) (i) $(9)$ This work is licensed under a Creative Commons Attribution-NonCommercial-NoDerivs 3.0 Unported License. The images or other third party material in this article are included in the article's Creative Commons license, unless indicated otherwise in the credit line; if the material is not included under the Creative Commons license, users will need to obtain permission from the license holder to reproduce the material. To view a copy of this license, visit http://creativecommons.org/licenses/by-nc-nd/3.0/ 